\title{
Hereditary Motor Sensory Neuropathy Type I Presenting as Scapuloperoneal Atrophy (Davidenkow Syndrome) Electrophysiological and Pathological Studies
}

\author{
Gabriel M. Ronen, Noel Lowry, John H. Wedge, Harvey B. Sarnat and Alan Hill
}

\begin{abstract}
A 14 year old boy with scapuloperoneal muscular atrophy, pes cavus, areflexia and distal sensory loss (Davidenkow syndrome) is described. Nerve conduction velocities were diminished. Sural nerve biopsy demonstrated a reduction in the number of myelinated fibers and early "onion-bulb" formation. These observations support the hypothesis that the scapuloperoneal amyotrophy associated with distal sensory loss may represent a variant of type I hereditary motor sensory neuropathy.
\end{abstract}

\begin{abstract}
RÉSUMÉ: Neuropathie motrice sensorielle héréditaire du type I présentée comme l'amyotrophie scapulo-péronière (syndrome de Davidenkow): des études eléctrophysiologiques et pathologiques Nous rapportons le cas d'un garçon âgé de 14 ans, atteint d'amyotrophie scapulo-péronière neurogène, de pied creux, l'aréflexie, et une perte de sensibilité distale (syndrome de Davidenkow). La vitesse de conduction des nerfs était diminuée. L'étude biopsique du nerf sural montra une baisse du nombre des fibres myélinisées ainsi que des formations «d'oignon» minimales. Ces observations appuyent l'hypothèse que l'amyotrophie scapulo-péronière associée à la perte sensible distale peut représenter une variante de la neuropathie motrice sensorielle héréditaire du type $\mathbf{I}$.
\end{abstract}

Can. J. Neurol. Sci. 1986: 13:264-266

Weakness and atrophy in a scapuloperoneal distribution may have a myopathic or neurogenic basis. Thus, it has been described in patients with muscular dystrophy, ${ }^{1.2}$ congenital myopathies, ${ }^{3}$ hereditary myopathies associated with cardiomyopathy, ${ }^{4}$ and inflammatory myopathies. ${ }^{5}$ Most neurogenic cases have been considered secondary to anterior horn cell disease.$^{6,7}$ However, scapuloperoneal amyotrophy may be associated with a distal sensory abnormality (Davidenkow syndrome) ${ }^{8}$ and may represent a variant of hereditary motor sensory neuropathy type I (HMSNI). ${ }^{5,9,10}$

This syndrome does not appear to be a distinct genetic entity and has been considered a variant of Charcot-Marie-Tooth disease. ${ }^{5,10}$

\section{CaSe RePort}

The patient is a 14 year old boy who presented with a slowly progressive unsteadiness of gait during the previous two years. At the time of referral he had difficulty climbing stairs. He is the fifth child of healthy, unrelated parents. Three brothers and one sister are healthy, and there is no family history of neuromuscular disease.

A dislocated right hip was diagnosed at one year of age. This was treated by traction, casting and splinting. Corrective surgery was performed at age seven years following unsuccessful conservative management.

Examination at age 14 years revealed a thin boy with mild kyphosis, elevation and winging of the scapulae, wasting of the muscles of the shoulder girdle, marked bilateral pes cavus, tight heel cords and atrophy of the anterior and lateral compartments of the leg muscles (Figure 1). There were no fasciculations. Power was reduced at the shoulder girdle and distally in the lower limbs. There was no proximal weakness of the lower limbs or distal weakness of the upper limbs. The gait was ataxic. Deep tendon reflexes were absent in all limbs, and the plantar responses were flexor. There was a mild intention tremor. Temperature, pain and vibration sensation was reduced distally in all limbs. Position sense was mildly diminished. Cranial nerve examination was normal. There were no palpable thickenings of peripheral nerves.

Investigations revealed normal levels of serum creatine kinase (CK), SGOT, and CSF protein. Computerized tomographic scan of the brain was normal.

From the Departments of Paediatrics and Clinical Neurological Sciences (Drs. Ronen, Lowry and Hill) and Orthopedics (Dr. Wedge), University of Saskatchewan, and Departments of Paediatrics. Pathology and Clinical Neurosciences. University of Calgary (Dr. Sarnat)

Received February 21, 1986. Accepted April 11, 1986

Reprint requests to: Dr. Alan Hill, Division of Neurology, Department of Paediatrics, University of British Columbia. British Columbia`s Children's Hospital, 4480 Oak Street, Vancouver, British Columbia, Canada V6H 3V4 

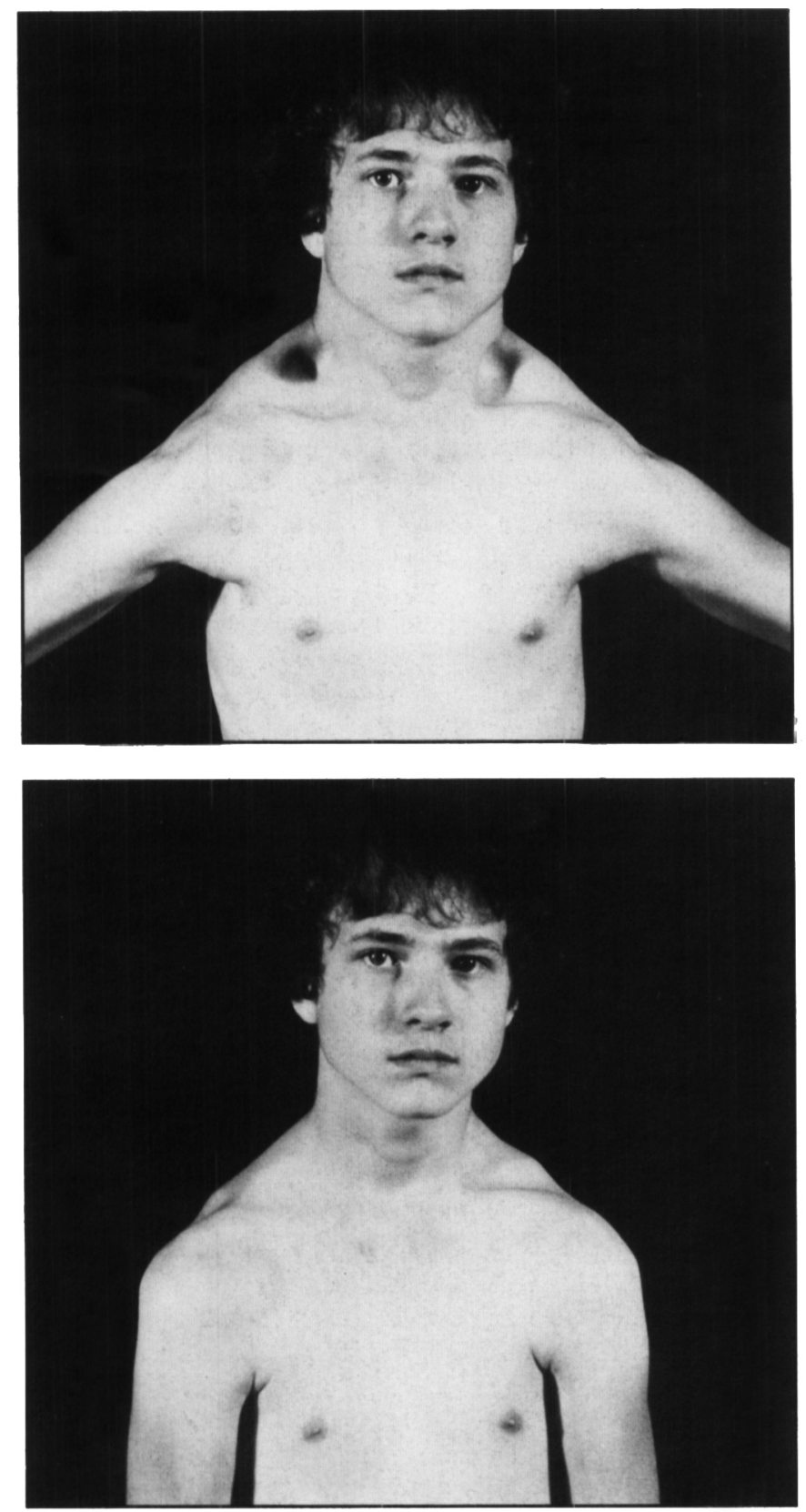

Figures $I A$ and $I B-$ Patient at age 14 years. The contour of the deltoid muscle is flattened and wasting is evident in the pectoralis major, sternocleidomastoid, biceps brachii and triceps brachii muscles. The trapezius muscle mounds when the arms are abducted, giving an appearance usually characteristic of facio-scapulo-humeral dystrophy.

Nerve conduction studies were abnormal as follows: in the median nerve compound muscle action potential (CMAP) $4.0 \mathrm{mv}$ (normal $>4.0$ ), distal latency (DL) $7.6 \mathrm{~m} / \mathrm{sec}$ (normal $<4.4 \mathrm{~m} / \mathrm{sec}$ ), and conduction velocity (CV) $23 \mathrm{~m} / \mathrm{sec}$ (normal $>49 \mathrm{~m} / \mathrm{sec}$ ). In the ulnar nerve the CMAP was $4.0 \mathrm{mv}$, the DL $4.0 \mathrm{~m} / \mathrm{sec}$ and CV $27 \mathrm{~m} / \mathrm{sec}$. In the posterior tibial nerve the CMAP was $0.3 \mathrm{mv}$, the DL $8.0 \mathrm{~m} / \mathrm{sec}$ and the CV 24 $\mathrm{m} / \mathrm{sec}$. There was no motor response in the peroneal nerve nor sensory response in the median, ulnar or sural nerves. The nerve conduction studies in the mother and three siblings were normal. In the father, the conduction studies were minimally abnormal as follows: motor responses in peroneal nerve, CMAP $2.0 \mathrm{mv}$., DL $7.5 \mathrm{~m} / \mathrm{sec}$ and CV $45 \mathrm{~m} / \mathrm{sec}$. The amplitude of the sensory nerve action potential in the median nerve was $0.008 \mathrm{mv}$ (normal $>0.010$ ) and the $\mathrm{DL}$ was $3.6 \mathrm{~m} / \mathrm{sec}$. The remainder of the conduction studies in the father were normal.
Muscle biopsy of the vastus lateralis showed polygonal muscle fibers of varying diameters with angular, atrophic fibers scattered throughout. Histochemical staining showed type-grouping involving all fascicles (Figure 2). The atrophic fibers were of both major histochemical types. These findings indicated chronic denervation and reinnervation.

Sections of sural nerve examined by both light and electron microscopy revealed a reduced number of large myelinated nerve fibers and increased interstitial collagen. Unmyelinated nerve fibers and small myelinated fibers appeared normal. Early "onion-bulb" formation was suggested by the concentric proliferation of Schwann cells around some myelinated nerve fibers (Figure 3). The biopsy was consistent with interstitial hypertrophic neuropathy.

\section{DISCUSSION}

In 1939, Davidenkow reviewed 13 patients with a syndrome of scapuloperoneal muscular atrophy associated with distal sensory loss. ${ }^{8}$ In most patients the disorder was inherited in a dominant fashion.

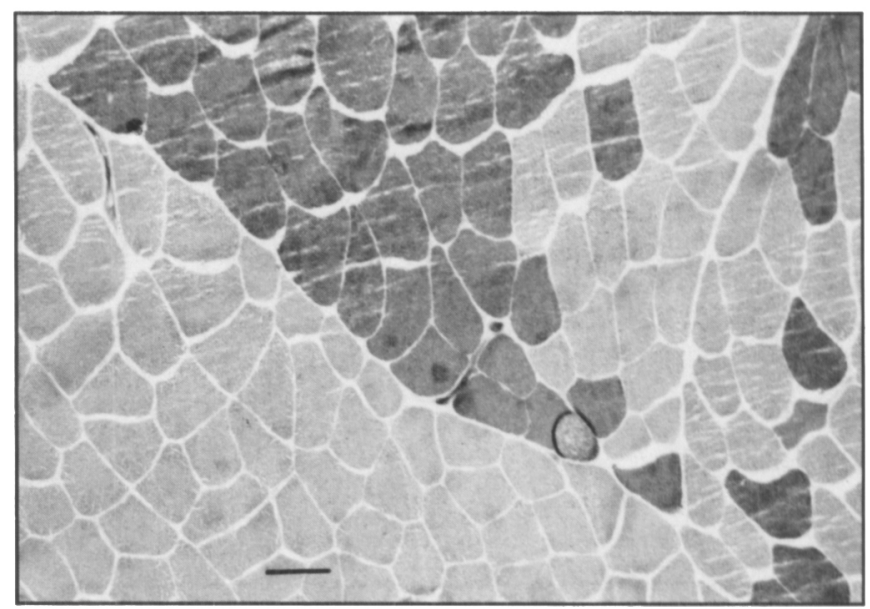

Figure 2 - Vastus lateralis muscle biopsy. Histochemical tope grouping denotes chronic denervation-reinnervation. Myofibrillar ATPase preincubated at pH 9.8. Bar $=40 \mu \mathrm{m}$.

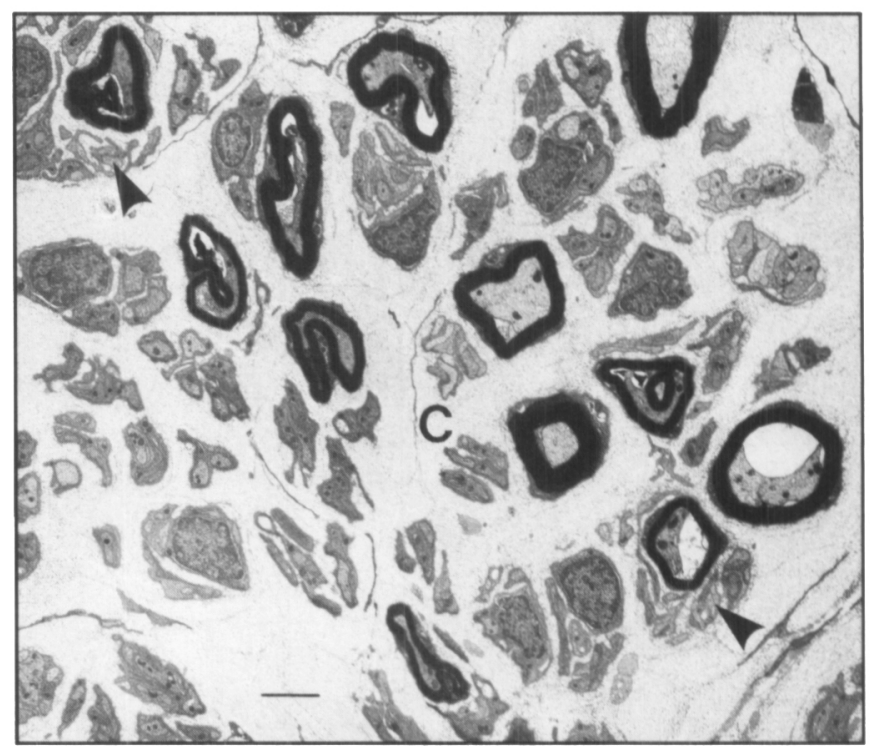

Figure $3-E . M$. cross-section of sural nerve. The total number of mvelinated nerve fibers is reduced. Interstitial collagen $(C)$ is proliferated. Early "onion bulb" formations are suggested by concentric layers of Schw'ann cells (arrowheads) around some myelinated fibers. Some of these laminae of Schwann cell processes enclose small unmyelinated axons. Bar $=3$ $\mu \mathrm{m}$. 
In recent years, 11 other cases with scapuloperoneal muscular atrophy and distal sensory loss have been reported..$^{5,9-13}$ The age of onset ranged from two and a half years to middle age. No clear mode of inheritance has been demonstrated; cases have been sporadic or inherited in an autosomal recessive or dominant fashion. Nerve conduction studies have been invariably abnormal. Demyelination with axonal degeneration has been demonstrated in nerve biopsies.

In our patient, the scapuloperoneal weakness and wasting together with distal sensory loss are consistent with a diagnosis of Davidenkow syndrome. Electrophysiological investigations, in particular the nerve conduction studies, and histological appearance of the sural nerve, indicate a demyelinating neuropathy of the HMSNI type. Consideration of these studies, together with a previous report of a patient with this syndrome whose sibling had classical Charcot-Marie-Tooth disease ${ }^{9}$ support the contention of Davidenkow ${ }^{8}$ and others ${ }^{5,9.10}$ that weakness and wasting in a scapuloperoneal distribution combined with distal hypesthesia may be due to HMSNI.

The mode of inheritance in our case is not clear. It could be sporadic or inherited in an autosomal recessive fashion. The fact that the nerve conduction studies in the father were only minimally abnormal and that the neurological examination was normal makes autosomal dominant inheritance unlikely, although autosomal dominant diseases in general have more variable clinical expressivity than do recessive or $\mathrm{X}$-linked diseases. A nerve biopsy of the father was not performed.

The demonstration of a demyelinating neuropathy in association with scapuloperoneal atrophy and distal sensory loss in the patient provides further support that Davidenkow's syndrome represents a variant of Charcot-Marie-Tooth disease (HMSNI).

\section{REFERENCES}

1. Oranski $W$. Ueber einen hereditaeren Typus progressiver Muskeldystrophie. Deutsch Z Nervenheilk 1927; 99: 147-155.

2. Kazakov VM, Bogorodinski DK, Skorometz AA. Myogenic scapuloperoneal syndrome. Muscular dystrophy in the K Kindred. Reexamination of the $\mathrm{K}$ family described for the first time by Oranski in 1927. Eur Neorol 1975; 13: 350-359.

3. Feigenbaum JA, Munsat TL. A neuromuscular syndrome of scapuloperoneal distribution. Bull Los Angeles Neurol Soc 1970; 35: 47-57.

4. Thomas PK, Calne DB, Elliott CF. X-linked scapuloperoneal syndrome. J Neurol Neurosurg Psychiatr 1972; 35: 208-215.

5. Serratrice G, Pellissier JF, Ponget J, Gastaut JL, et al. Les syndromes scapulo-péroniers. Rev Neurol (Paris) 1982; 138: 691-711.

6. Stark D. Étude clinique et génétique d'une famille atteinte d'atrophie musculaire progressive neurale. J Genet Hum 1958; 7: 1-32.

7. Kaeser HE. Scapuloperoneal muscular atrophy. Brain 1965; 88: 407-418.

8. Davidenkow S. Scapulo-peroneal amyotrophy. Arch Neurol Psychiatr 1939; 41: 694-701.

9. Harding AE, Thomas PK. Distal and scapuloperoneal distribution of muscle involvement occurring within a family with Type 1 hereditary motor and sensory neuropathy. J Neurol 1980; 224: 17-23.

10. Serratrice G, Pellissier JF, Pouget J. Trois cas d'amyotrophie scapulopéronière neurogène (syndrome de Davidenkow). Rev Neurol (Paris) 1984; 140: 738-740.

11. Tsukagoski H, Takasu T, Yoshida $\mathbf{M}$, et al. A family with scapuloperoneal muscular atrophy. Clin Neurol (Tokyo) 1969; 9: $511-517$.

12. Toghi H, Tsukagashi H, Toykura Y. Neurogenic scapuloperoneal syndrome with autosomal recessive inheritance. Clin Neurol (Tokyo) 1971; 11: 215-220.

13. Schwartz MD, Swash M. Scapuloperoneal atrophy with sensory involvement: Davidenkow's syndrome. J Neurol Neurosurg Psychiatry 1975 ; 38 : 1003-1007. 